\title{
Prevalence of rapid repeat pregnancy and associated factors in adolescents in Caruaru, Pernambuco
}

\author{
Ana Paula dos Santos Albuquerque 1 \\ Ana Carolina Rodarti Pitangui 2 \\ Poliana Maria Gaspar Rodrigues 3 \\ Rodrigo Cappato de Araújo 4
}

\footnotetext{
1 Centro Universitário do Vale do Ipojuca, Caruaru, PE. Brasil. CEP: 50100-010. E-mail: carolina.pitangui@upe.br

3 Programa de Pós-Graduação Associado em Enfermagem UPE/UEPB, Recife, PE, Brasil.

4 Programa de Pós-graduação Associado em Educação Física UPE/UFPB, Recife, PE, Brasil.
}

2 Programa de Mestrado em Hebiatria, Universidade de Pernambuco. Recife, PE. Brasil. Av. Gov. Agamenon Magalhães, S/N - Santo Amaro, Recife - PE,

\begin{abstract}
Objectives: to determine the prevalence and factors associated with the rapid repeat pregnancy (RRP) in pregnant adolescents.

Methods: a cross-sectional study was carried out with pregnant adolescents assisted at the Family Health Strategies in Caruaru-PE from March to August 2013. A questionnaire with sociodemographic, economic, schooling, gynecological, obstetric and contraceptive characteristics was used. The data were analyzed in the Statistical Package for Social Sciences (SPSS), version 20. Binary logistic regression models were used.

Results: among the 204 pregnant adolescents interviewed, the data of $26.5 \%(n=54)$ multiparous were analyzed. The occurrence of RRP was 42.6\% $(n=23)$ [95\% CI 29.2356.79]. The variables associated with RRP were non-use of contraceptive methods [OR 7.40 (CI95\% 1.56-3.49)] and no previous pregnancy planning [OR 0.19 (95\% CI 0.05-0.78)].

Conclusions: the percentage of RRP in adolescents was high. The non-use of contraceptive methods increased the chances of RRP, while the no previous pregnancy planning decreased the chances of adolescents getting pregnant again without previous programming.

Key words Pregnancy in adolescence, Sexual behavior, Reproductive health
\end{abstract}




\section{Introduction}

Pregnancy at adolescence is a single and random episode since, for some adolescents it ends up occurring again. This condition, when it happens in a period of in between pregnancies up to 24 months, is defined as Rapid Repeat Pregnancy (RRP), it is considered a risky situation due to a short period for the female organism to recover for a new safe obstetric development, especially at adolescence. ${ }^{1-5}$

Several maternal complications may occur during the prenatal period, childbirth and puerperium, due to these situations, they are considered to be more severe, furthermore, negative results may also occur in the social and economic context, as well as neonatal complications such as prematurity, low birth weight, preterm infants and increased neonatal and infant mortality. 1,6-8

Teenagers who get pregnant again in less than two years are less likely to return to school or become economically self-sufficient than those who start reproduction later, and their children have a higher probability of presenting behavioral and emotional problems when compared to other children.3,9-12 Women starting motherhood during adolescence tend to have a greater number of children throughout their reproductive life.4,10

Generally, the first pregnancy is not planned, and sometimes unwanted; thus, it is high the probability of the following pregnancies acquire the unwanted character of the first.1,3 The repetition of a new unwanted pregnancy at adolescence occurs on a scale of one to five young girls; however, neither the experience of getting pregnant nor its consequences are considered to be effective to develop a responsible sexual behavior and capable of breaking a vicious circle. 3,13

Effective measurements to significantly reduce rates of teenage pregnancies, including the rapid repeat pregnancies that are based on the use of contraceptives. However, many adolescents are infrequent users of these methods. The discontinuation ofncontraceptive puts teenage mothers in high risk, since many get pregnant again within 12 months after childbirth. ${ }^{9-11}$

Some reasons may be described as determinant factors for this discontinuation, such as: the teenager does not like the side effects of the oral contraceptives, the unplanning sexual activities and the absence of receiving advice from the health team regarding the immediate postpartum. 2,5,14,15

The understanding of factors that contribute to teenage pregnancy and its repetition are fundamental to the development of adequate interven- tions. ${ }^{16}$ As for this, and as a result of the RRP threaten the well-being and the future of adolescents due to physical, emotional and social risks which it entails, the objective of this study was to determine the prevalence of RRP and associated factors in adolescents attended at the Family Health Strategies (ESF) in the city of Caruaru-PE.

\section{Methods}

A cross-sectional, observational and correlational study that consisted in the analysis of the primary data of pregnant adolescents from the Family Health Strategies (ESF) in the city of Caruaru-PE in the period from March to August 2013.

The city comprises of 42 ESFs, , 26 are in the urban area and 16 in the rural area. The distribution of the collecting locations was performed by adopting a percentage of $57 \%$ of the ESF, which corresponded to the amount of 24 ESFs. The ESFs were randomization through a computer program, which corresponded to 16 ESFs located in the urban area and 08 in the rural area. Finally, the selection of pregnant women was performed having defined a minimum number of eight pregnant women for each ESF.

The WINPEPI program (version 11.39) was used to quantify the sample. . A population of 420 pregnant adolescents was considered enrolled at the ESFs. (data from the Secretary of Health from the city of Caruaru), a confidence level of $95 \%$, the estimated proportion of $18.3 \%$, in RRP in adolescence 5 an absolute precision of $5 \%$ and a loss of $20 \%$, obtaining the necessary minimum value of 186 pregnant adolescents.

The inclusion criteria were: to be an adolescent according to the World Health Organization (WHO) aged between 10 and 19 years, have experienced more than one pregnancy less than or at 24 months and performed prenatal care regularly at the ESF in urban or rural areas in the city of Caruaru-PE. Adolescents who presented medical diagnostics as, neurological pathologies or alterations in their physical, behavior and/or psychological state, and that were unable to fill out the questionnaire were excluded.

For data collection, a structured questionnaire was useed that analyzed three sets of variables: 1) socio-demographic and economic (parents' marital status; marital status; skin color; monthly income ; schooling, the mother's schooling level; father's schooling level); 2) gynecological obstetric and contraceptives (age of the first intercourse; menarche age; time returned to sexual activity in the 
first pregnancy; age of the first pregnancy; previous pregnancy planning; current pregnancy planning; and the use of contraceptive method); and 3) schooling (dropped out and failed). All the questions were formulated directly and the answers classified among the alternatives contained in the questionnaire. The questions were presented in a schematic manner, through the use of multiplechoice questions, aiming to facilitate the answers.

The data tabulation procedure was performed in the Microsoft Excel by double data entry. The data analysis was done by using the Statistical Package for the Social Sciences (SPSS) program, version 20. The descriptive analysis included for the categorical variables, the frequency distribution (relative and absolute) and $95 \%$ confidence interval $(95 \% \mathrm{CI})$ for the proportions. For the numeric variables, mean, median, standard deviation, maximum and minimum values were calculated.

Models of univariate logistic regression were constructed to test the isolated association between the dependent variable (RRP) and each independent variable, in addition to analyzing the variables used in the model, exploring the possible confounding factors and identifying the need to adjust the statistical analyzes. The binary logistic regression was applied, by means of the odds ratio (OR) and $95 \%$ CI to express the association degree between the independent and dependent variables, using the adjustment for potential confounding factors. After obtaining the predictive variables of the final model, the interaction occurrence was tested. For the final model, the variables with the significance level of $p<0.20$ in univariate regression were selected. Finally, the Hosmer-Lemeshow test was applied. In all the tests the statistical significance was considered as the value of $p<0.05$

This research followed all the Resolution precepts of the number 466/12 from the National Health Council (CNS) and the Guidelines from the Child and Adolescent's Statute (ECA), and was approved by the Human Research Ethics Committee at the Universidade de Pernambuco - CEPUPE under the number of CAAE: 12534813.4.0000.5207. All of the adolescents were invited voluntarily to participate in this research, and those who accepted had to sign the Informed Consent Form (TCLE). In the case of the adolescents were under 18 years of age, it was necessary the parents' or the guardians' permission.

\section{Results}

204 adolescents who were pregnant were inter- viewed. Most of them were in their first pregnancy $73.5 \%(\mathrm{n}=150)$ [95\% CI 66.92-79.45], with an average of pregnancies of $1.37 \pm 0.71$ children, with a minimum of one and a maximum of five pregnancies. Regarding to the RRP $26.5 \%(\mathrm{n}=54)$ were multiparous. The occurrence of RRP among these adolescents was $42.6 \%(\mathrm{n}=23)$ [95\% CI 29.23 56.79]. The average age of the sample was $17.03 \pm$ 1.52 years and at the first pregnancy was $16.44 \pm$ 1.57 years, both with a minimum of 13 years and maximum of 19.

In Table 1 the results among RRP, the sociodemographic and economic variables can be seen. It was observed that only the monthly income variable presented values to be entered in the regression model. And that $60.9 \%(n=14)$ of the adolescents with repeated pregnancy presented a monthly income inferior of one minimum wage.

The adolescents' gynecological, obstetric and contraceptives variables are shown in Table 2. The logistic regression analysis of the permanence variables of contraceptive methods and the previous pregnancy planning were considered. It is worth noting that $44.40 \%(\mathrm{n}=24)$ [ $95 \%$ IC $30.92-58.60$ ] multiparous mentioned to have returned to their sexual activities in a period less than or equal to 40 days.

Regarding to schooling variables, it can be observed in the logistic regression analysis that the variable that remained was dropping out of school (Table 3). However, it can be noticed that the presence of dropping out of school and failing school were elevated in both pregnant women either those who had repeated pregnancy or those who did not. In the analysis of multiparous, it was found that $81.48 \%(\mathrm{n}=44)$ [95\% CI $68.57-90.75$ ] of adolescents reported dropping out and $68.52 \%(\mathrm{n}=37)$ [95\% CI 54.45 - 80.48] were failing school.

Finally, the logistic regression analysis can be observed in the final model and the variables that remained associated with the outcome were: contraceptive methods and previous pregnancy planning (Table 4). The result found in the Hosmer-Lemeshow test was $88.40 \%$. Based on the data, it is possible to see that the non-use of contraceptive methods increased more than seven times the chances of adolescents presenting RRP [OR 7.40 (95\% CI 1.563.49)], while the non- planning performance of the management before decreasing the chances of the adolescent presenting a new pregnancy without prior programming [OR 0.19 (95\% CI 0.05- 0.78)]. 
Table 1

Logistic regression analysis between rapid repeat pregancy and the sociodemographic and economic variables.

\begin{tabular}{|c|c|c|c|c|c|c|}
\hline \multirow{2}{*}{ Independent variables } & \multicolumn{2}{|c|}{ Presence of RRP } & \multicolumn{2}{|c|}{ Absence of RRP } & \multirow{2}{*}{ OR (Cl95\%) } & \multirow{2}{*}{$p$} \\
\hline & $\mathrm{n}$ & $\%$ & $\mathrm{n}$ & $\%$ & & \\
\hline Parents' marital status & & & & & & 0.325 \\
\hline Live together & 12 & 52.2 & 12 & 38.7 & $1.72(0.58-5.14)$ & \\
\hline Separated/Divorced & 11 & 47.8 & 19 & 61.3 & 1 & \\
\hline Marital Status & & & & & & 0.529 \\
\hline Married / Stable Union & 16 & 69.6 & 19 & 61.3 & $1.44(0.45-4.53)$ & \\
\hline Others & 07 & 30.4 & 12 & 38.7 & 1 & \\
\hline Skin Color & & & & & & 0.389 \\
\hline Black/Mixed & 05 & 21.7 & 04 & 12.9 & $1.87(0.44-7.94)$ & \\
\hline White/Yellow & 18 & 78.3 & 27 & 87.1 & 1 & \\
\hline Monthly Income & & & & & & $0.169 *$ \\
\hline Lower than 1 minimum wage & 14 & 60.9 & 13 & 41.9 & $2.15(0.71-6.47)$ & \\
\hline Between 1 and 2 minimum wages & 09 & 39.1 & 18 & 58.1 & 1 & \\
\hline Schooling Level & & & & & & 0.600 \\
\hline Up to 8 years & 18 & 78.3 & 26 & 83.9 & $0.69(0.17-2.74)$ & \\
\hline Over 8 years & 05 & 21.7 & 05 & 16.1 & 1 & \\
\hline Mother's schooling Level & & & & & & 0.627 \\
\hline Up to 8 years & 21 & 91.3 & 27 & 87.1 & $1.55(0.26-9.32)$ & \\
\hline Over 8 years & 02 & 8.7 & 04 & 12.9 & 1 & \\
\hline Father's schooling Level & & & & & & 0.902 \\
\hline Up to 8 years & 21 & 91.3 & 28 & 90.3 & $1.12(0.17-7.34)$ & \\
\hline Over 8 years & 02 & 8.7 & 03 & 9.7 & 1 & \\
\hline
\end{tabular}

RRP $=$ Rapid Repeat Pregnancy *variables with $p<0.20$ maintained in the logistic regression model to control confusion. 
Logistic regression analysis among rapid repeat pregancy and gynecologic, obstretic and contraceptives variables.

\begin{tabular}{|c|c|c|c|c|c|c|c|}
\hline \multirow{2}{*}{ Independent variables } & \multicolumn{2}{|c|}{ Presence of RRP } & \multicolumn{2}{|c|}{ Absence of RRP } & \multirow{2}{*}{ OR } & \multirow{2}{*}{$\mathrm{Cl} 95 \%$} & \multirow{2}{*}{$p$} \\
\hline & $\mathrm{n}$ & $\%$ & $\mathrm{n}$ & $\%$ & & & \\
\hline Age at first sexual activity & & & & & & & 0.503 \\
\hline$\leq 14$ years old & 12 & 52.2 & 19 & 61.3 & 0.68 & $0.23-2.05$ & \\
\hline Between 15 and 18 years' old & 11 & 47.8 & 12 & 38.7 & & & \\
\hline Menarche age & & & & & & & 0.369 \\
\hline$\leq 13$ years old & 17 & 73.9 & 26 & 83.9 & 0.54 & $0.14-2.07$ & \\
\hline$\geq 14$ years old & 06 & 26.1 & 05 & 16.1 & & & \\
\hline Return to have sexual activity & & & & & & & 0.667 \\
\hline$\leq 40$ days & 11 & 47.8 & 13 & 39.1 & 1.26 & $0.42-3.75$ & \\
\hline$>41$ days & 12 & 52.2 & 08 & 58.1 & & & \\
\hline Age of first pregnancy & & & & & & & 0.250 \\
\hline$\leq 14$ years old & 03 & 13.0 & 08 & 25.8 & 0.43 & $0.10-1.84$ & \\
\hline Between 15 and 19 years' old & 20 & 87.0 & 23 & 74.2 & & & \\
\hline Previous Pregnancy Planning & & & & & & & $0.042 *$ \\
\hline No & 10 & 43.5 & 22 & 71.0 & 0.31 & $0.10-0.97$ & \\
\hline Yes & 13 & 56.5 & 09 & 29.0 & & & \\
\hline Current Pregnancy Planning & & & & & & & 0.551 \\
\hline No & 13 & 56.5 & 20 & 64.5 & 0.71 & $0.23-2.15$ & \\
\hline Yes & 10 & 43.5 & 11 & 35.5 & & & \\
\hline Use of contraceptive method & & & & & & & $0.012 *$ \\
\hline No & 11 & 47.8 & 05 & 16.1 & 4.76 & $1.35-16.7$ & \\
\hline Yes & 12 & 52.2 & 26 & 83.9 & & & \\
\hline
\end{tabular}

RRP $=$ Rapid Repeat Pregnancy *variables with $p<0.20$ maintained in the logistic regression model to control confusion.

Table 3

Logistic regression analysis between rapid repeat pregnancy and school variables.

\begin{tabular}{|c|c|c|c|c|c|c|c|}
\hline \multirow{2}{*}{ Independent Variables } & \multicolumn{2}{|c|}{ Presence of RRP } & \multicolumn{2}{|c|}{ Bsence of RRP } & \multirow{2}{*}{ OR } & \multirow{2}{*}{$\mathrm{Cl} 95 \%$} & \multirow{2}{*}{$p$} \\
\hline & $\mathrm{n}$ & $\%$ & $\mathrm{n}$ & $\%$ & & & \\
\hline Dropping out of School & & & & & & & $0.109 *$ \\
\hline Yes & 21 & 91.3 & 23 & 74.2 & 3.65 & $0.69-19.1$ & \\
\hline No & 02 & 8.7 & 08 & 25.8 & & & \\
\hline Failed at School & & & & & & & 0.887 \\
\hline Yes & 16 & 69.6 & 21 & 67.7 & 1.08 & $0.34-3.48$ & \\
\hline No & 07 & 30.4 & 10 & 32.3 & & & \\
\hline
\end{tabular}

RRP $=$ Rapid Repeat Pregnancy *variables with $p<0.20$ maintained in the logistic regression model to control confusion. 
Final model of logistic regression of variables that maintained the association with the rapid repeat pregnancy.

\begin{tabular}{lcc}
\hline Variables & OR (IC 95\%) & $p$ \\
\hline $\begin{array}{l}\text { Contraceptive methods } \\
\quad \text { No }\end{array}$ & $7.40(1.56-34.9)$ & $0.012^{*}$ \\
$\quad$ Yes & 1 & $0.022^{*}$ \\
Previous Pregnancy Planning & $0.19(0.05-0.78)$ & 1 \\
$\quad$ No & & \\
$\quad$ Yes & & \\
${ }^{*} p \leq 0.05$. &
\end{tabular}

\section{Discussion}

The data of our study found that most of the sample was based in the first pregnancy, with an average age of the first pregnancy at 16.44 years. This condition can present benefits to avoid a repeated pregnancy, since $t$ getting pregnant under the age of 15 years puts the pregnancy at a higher risk level, due to a great tendency of higher rates in prematurity and low birth weight. 17

However, $26.5 \%$ of the evaluated adolescents reported to be multiparous and showed high occurrence of RRP, with a prevalence of $42.6 \%$, that is, a high proportion of these adolescents had a new pregnancy in less than two years from their last pregnancy.

Lower values of prevalence were observed in other studies, such as the research developed in South Africa, despite of having found a high percentage of adolescents $(75.0 \%)$ with an interval between pregnancies were less than two years, prevalence of repeated pregnancy of $17.6 \%$ were observed. ${ }^{16}$ In a study carried out by the Centers for Disease Control and Prevention (CDC) in the USA in 2010, in which found that, 364,859 births of adolescents aged between $15-19$ years, $18.3 \%$ represented the repeated births. The majority $(85.7 \%)$ was of repeated births of a second child, but some adolescents (12.6\%) gave birth to a third child,, and a few births $(1.7 \%)$ the mothers were already in their fourth and sixth child. This report shows that almost one in five births among adolescents in 2010 was considered a birth of repetition. 5

Higher prevalences were found by other authors, ${ }^{3}$ who observed recurrence rates of the second pregnancy , $66.7 \%$, the third pregnancy $30.3 \%$ and the fourth pregnancy $3.0 \%$. These data reveal that the multiparity or recurrence of pregnan- cies have become a more and more common condition in the Brazilian maternities without occurring even the interval between pregnancies $t$ which are deemed appropriate for the maintenance and recovery of the mother's health.

Thus, it is believed that the highest prevalence of RRP in our study and in other Brazilian studies can be explained due to the difference in socio-cultural and economic structure in the country. In addition, low schooling level is still present in various locations in Brazil, and this can be one of the collaborating factors for the occurrence of repeated pregnancy. Many times, the adolescents, after becoming a mother, cannot return to school to finish their studies, comprising their future perspective, which they end up perpetuating the cycle of poverty and becoming a strong indicator for repetition of the pregnancy. 3 Typically, the adolescents tend to stop studying when they get pregnant for the first time, and with recurrent pregnancies they remain permanently out of school. ${ }^{10}$

Confirming with this condition, our study found a high prevalence of among pregnant women dropping out of school and failing school, and a higher percentage among women with repetition of pregnancy. Such fact has been demonstrated as the main characteristic associated with the social issue of pregnancy in adolescence. 18 Dropping out of school is a concerning situation, once it is responsible for causing worsening in the socioeconomic conditions of these adolescents, restricting their possibilities in a professional qualification and insertion in the labor market, thereby causing dependence on the partner or family. ${ }^{3}$ This financial dependence associated with dropping-out may contribute to the victimization of young mothers, as well as making the adolescents in need of autonomy to execute decisions that involve their future and the child. 18 
It is necessary to involve pregnant adolescents and parents in the effective health programs, targeted to this specific audience, as a way of reducing its repetition. Advice on the spacing of births, contraception during pregnancy and the provision of long-term reversible contraceptives, Long-Acting Reversible Contraception (LARCs) - at immediate postpartum period are examples of how to facilitate the access to contraceptive pills for teenage mothers. ${ }^{8}$ However, there should be caution with the direct providing of contraceptives by the health service, once even increasing the use of contraceptives, this intervention strategy is not feasible in environments where young people do not have access to health services. 19 It should be emphasized also the importance of the healthcare team in guiding the choice of contraceptive method for adolescent mothers during the postpartum period, since this practice has been shown to prevent pregnancy thereafter. 5

In our study, the non-use of contraceptive methods has increased more than seven times the chances of evaluated adolescents presenting RRP while the non-completion of previous pregnancy planning decreased the chances of adolescents presenting new pregnancies without prior programming.

Although many adolescents present history of contraceptive use before, generally the use is not supported after the pregnancy or it is interrupted within a year. The continuity of contraception over a long term is certainly a challenge for adolescents who are at risk of abandoning contraception between the relationships and resuming sexual activities before restarting the use of contraception. 16

A strategy that has exhibited positive results and that should be encouraged by the health team and by family planning programs is the use of LARCs, which have demonstrated a rate of continuation higher than other methods at 12 months and 2 years. ${ }^{20}$ LARCs are an effective, secure and acceptable tool to prevent pregnancy in adolescence and its recurrence, 21 but as all contraceptive methods this one may present adverse effects, thus, counselling and support are crucial for the teenagers. ${ }^{20}$ The moment of insertion of the implant or the IUD during the immediate postpartum period is more effective than the delay of four to six weeks, without adverse clinical outcomes reported by either the breastfeeding mother as for the breastfed infant. 20

However, the decision-making on the searching or preventing a rapid repeat pregnancy is complex for teenage mothers. Encouraging the approval of
LARCs could not only protect those who have intention to avoid a repetition of pregnancy, but may give time for young women with ambivalence to find their intention. ${ }^{22}$ In spite of this, so that these measurements really work, professionals need to be aware of the potential barriers and the facilitators, such as adequacy and method preferences. 23

The recurrence of pregnancy can be considered a more dramatic condition, as it indicates that the first early pregnancy has not brought a significantly stronger call to prevent the occurrence of a new pregnancy. The repetition of this event can lead to the disorganization of the family, dropping out of school, social and labor withdrawal, as well as encourage emotional issues. ${ }^{3}$ It is believed that the fact that the first pregnancy was without planning, but resulted in a strong change in women's lives, that it can make the subsequent pregnancy occur in a way as planned by the couple. It is also noted that the occurrence of a pregnancy makes the adolescent less embarrassed to seek information about sex, demonstrating greater engagement in family planning service, and therefore healthy reproductive practices. 24

However, it is important to recognize some limitations in this present study, such as the specific sample from only one city in the state of Pernambuco, a condition that causes these results in this study not to be representative for other locations, , therefore, the conclusions are found to be generalized. All responses were based on the adolescents' self-report, which could lead to memory bias; still, it was a small number of multiparous sample, a fact that may have limited the associations found.

We suggest that further studies with larger samples, from different regions, and with longitudinal design, have as a purpose to verify if other environmental and social factors may influence pregnancy and its recurrence in adolescents.

Finally, it can be inferred from this study that most of the sample was based on first time pregnancy $t$, but in the multiparous it was verified a high percentage of RRP. The non-use of contraceptive methods was the condition that increased the chances of adolescents presenting RRP and the failure on planning their first pregnancy was the factor that decreased the chances of adolescents getting pregnant again without prior programming. It is of extreme importance that health professionals receive regular training in order to provide a service for detailed advice on contraception and family planning for the adolescents. 


\section{References}

1. Berlofi LM, Alkmin ELC, Barbieri M, Guazzelli CAF, Araújo FF. Prevenção da reincidência de gravidez em adolescentes: efeitos de um Programa de Planejamento Familiar. Acta Paul Enferm. 2006; 19(2): 196-200.

2. Lewis LN, Doherty DA, Hickey M, Skinner SR. Predictors of sexual intercourse and rapid-repeat pregnancy among teenage mothers: an Australian prospective longitudinal study. Med J Aust. 2010; 193(6): 338-42.

3. Manfredo VA, Cano MAT, Santos BMDO. Reincidência de gravidez em adolescentes: retrato de uma realidade. Rev APS. 2012; 15(2): 192-8.

4. Ferreira CL, Braga LP, Mata ÁNDS, Lemos CA, Maia EMC. Repetição de gravidez na adolescência: estudos sobre a prática contraceptiva em adolescentes. Estudos e Pesquisas em Psicologia. 2012; 12(1): 188-204.

5. Centers for Disease Control and Prevention (CDC). Vital signs: Repeat births among teens-United States, 2007-2010. MMWR Morb Mortal Wkly Rept. 2013; 62(13): 249

6. Vieira CL. Gestação na adolescência: avaliação de desfechos adversos ao nascimento e repetição rápida da gestação [Dissertação de Mestrado]. Rio de Janeiro: Instituto de Estudos em Saúde Coletiva, Universidade Federal do Rio de Janeiro; 2010

7. Charlton BM, Corliss HL, Missmer SA, Rosario M, Spiegelman D, Austin SB. Sexual orientation differences in teen pregnancy and hormonal contraceptive use: an examination across 2 generations. Am J Obstet Gynecol. 2013; 209(3): 204-e1.

8. Silva ADAA, Coutinho IC, Katz L, Souza ASR. Fatores associados à recorrência da gravidez na adolescência em uma maternidade escola: estudo caso-controle A casecontrol study of factors associated with repeat teen pregnancy based on a sample. Cad Saúde Pública. 2013; 29(3): 496-506.

9. Wilson EK, Samandari, G, Koo HP, Tucker C. Adolescent mothers' postpartum contraceptive use: a qualitative study. Perspect Sex Reprod Health. 2011; 43(4): 230-37.

10. Padin MDFR, Silva RDSE, Mitsuhiro SS, Chalem E, Barros MM, Guinsburg R, Laranjeira R. Repeat pregnancies among adolescents in a tertiary hospital in Brazil. J Reprod Infant Psychol. 2012; 30(2), 193-200.

11. Wilson EK, Fowler CI, Koo H.P. Postpartum contraceptive use among adolescent mothers in seven states. J Adolesc Health. 2013; 52(3): 278-83.

12. Pinto JF, Oliveira VJ, Souza MC. Perfil das adolescentes grávidas no setor saúde do Município de Divinópolis. Rev Enf Centro-Oeste Mineiro. 2013; 3(1): 518-30.

13. Chalem E, Mitsuhiro SS, Ferri CP, Barros MCM, Guinsburg R, Laranjeira R. Gravidez na adolescência: perfil sócio-demográfico e comportamental de uma população da periferia de São Paulo, Brasil Teenage pregnancy: beha- vioral and socio-demographic profile of an urban. Cad Saúde Pública. 2007; 23(1): 177-86.

14. Ramathuba DU, Khoza LB, Netshikweta ML. Knowledge, attitudes and practice of secondary school girls towards contraception in Limpopo Province. Curationis. 2012; 35(1): E1-7.

15. Bitzer J. Oral contraceptives in adolescent women. Best Pract Res Clin Endocrinol Metab. 2013; 27(1): 77-89.

16. Mphatswe W, Maise H, Sebitloane M. Prevalence of repeat pregnancies and associated factors among teenagers in KwaZulu-Natal, South Africa. Int J Gynaecol Obstet. 2016; 133(2): 152-5.

17. Caminha NDO, Costa CCD, Brasil RFG, Sousa DMDN, Freitas LV, Damasceno AKD C. The profile of the puerperal adolescents treated in a referenced maternity in FortalezaCeará. Esc Anna Nery. 2012; 16(3): 486-92.

18. Nery IS, Gomes KRO, Barros IDC, Gomes IS, Fernandes ACN, Viana LMM. Factors associated with recurrent pregnancy following initial teenage pregnancy in Piauí, Brazil. Epidemiol Serv Saúde. 2015; 24(4): 671-80.

19. Hindin MJ, Kalamar AM, Thompson TA, Upadhyay UD. Interventions to Prevent Unintended and Repeat Pregnancy Among Young People in Low- and Middle-Income Countries: A Systematic Review of the Published and Gray Literature. J Adolesc Health. 2016; 59 (Suppl 3): S8-S15.

20. Tocce KM, Sheeder JL, Teal SB. Rapid repeat pregnancy in adolescents: do immediate postpartum contraceptive implants make a difference? Am J Obstet Gynecol. 2012; 206(6): 481. e1-7.

21. Winner B, Peipert JF, Zhao Q, Buckel C, Madden T, Allsworth JE, Allsworth JE, Secura GM. Effectiveness of long-acting reversible contraception. N Engl J Med. 2012; 366(21): 1998-2007.

22. Conroy KN, Engelhart TG, Martins Y, Huntington NL, Snyder AF, Coletti KD, Cox JE. The Enigma of Rapid Repeat Pregnancy: A Qualitative Study of Teen Mothers. J Pediatr Adolesc Gynecol. 2016; 29(3): 312-7.

23. Charles JM, Rycroft-Malone J, Aslam R, Hendry M, Pasterfield D, Whitaker R. Reducing repeat pregnancies in adolescence: applying realist principles as part of a mixed methods systematic review to explore what works, for whom, how and under what circumstances. BMC Pregnancy Childbirth. 2016; 16(1): 271.

24. Moura LNBD, Gomes KRO. Family planning: use of the health services by young people with experience of pregnancy. Ciênc Saúde Coletiva. 2014; 19(3): 853-63.

Received on May 13, 2016

Final version submitted on January 04, 2017

Approved on April 07, 2017 